\title{
Perspectivas Teóricas do Reconhecimento de Identidades Sexuais Frente aos Direitos Humanos e ao Direito Fraterno
}

\author{
Theoretical Perspectives of the Recognition of Sexual Identities in Face of \\ Human Rights and the Fraternal Law
}

\author{
Charlise Paula Colet Gimenez ${ }^{1}$ \\ Paulo Adroir Magalhães Martins ${ }^{1}$ \\ Rosângela Angelin ${ }^{1}$ \\ ${ }^{1}$ Universidade Regional Integrada do Alto Uruguai e das Missões (URI), Santo Ângelo, RS, Brasil
}

\begin{abstract}
Resumo: As identidades ganham significados nos contextos sociais. Desse modo, a partir de um estudo hipotético-dedutivo, pretende-se refletir acerca da importância do reconhecimento identitário das sexualidades para efetivar direitos humanos, apresentando-se as contribuições e os limites do Direito Fraterno sobre esse tema. Percebe-se que o reconhecimento identitário sexual evoluiu em termos jurídicos, mas segue envolto de preconceitos e estereótipos, refletindo na promoção e no exercício desses direitos. O Direito Fraterno contribui para reflexões das realidades a partir de premissas voltadas para a alteridade, o que facilita o reconhecimento de identidades sexuais não heteronormativas, muito embora seja necessário promover uma profunda mudança cultural.
\end{abstract}

Palavras-chave: Reconhecimento. Identidades Sexuais. Direito Fraterno.

\begin{abstract}
Identities gain meaning in social contexts. Therefore, based on a hypotheticaldeductive study, it is intended to reflect on the importance of the identity recognition of sexualities to accomplish human rights, presenting the contributions and limits of the Fraternal Right on this theme. It is noticed that the recognition of sexual identity has evolved in legal terms, but is still surrounded by prejudices and stereotypes, reflected in the promotion and exercise of these rights. The Fraternal Law contributes to reflections of realities based on premises aimed at alterity, which facilitates the recognition of non-heteronormative sexual identities, although it is needed profound cultural change.
\end{abstract}

Keywords: Identity Recognition. Sexualities. Fraternal Law.

Recebido em: 03/04/2018

Revisado em: 31/07/2018

Aprovado em: 11/08/2018 


\section{Introdução}

As sexualidades não merecem uma abordagem enquanto situações que necessitam de disciplina ética ou de intervenções terapêuticas. As sexualidades carecem de serem vislumbradas como questões atreladas aos princípios fundamentais dos direitos humanos, num contexto social-democrático, perpassando pelos conhecimentos, experiências e vivências das pessoas, assim como estar presente nos debates de todas as áreas do conhecimento. A abordagem jurídica e social precisa pautar esse tema no respeito aos sujeitos humanos e não na visão essencialista e biologizante, que, geralmente, está impregnada no discurso jurídico. Abordar as identidades humanas e discutir sobre tudo que as envolve, num patamar em que a cultura e o poder estão presentes, não é uma tarefa simples, pois exige debates das relações dos sujeitos com as coletividades em determinados contextos socioculturais. As essencialidades identitárias não são suficientes para interpretar o sujeito na sociedade contemporânea; ou seja, não é mais possível pensar na ideia de identidade singular, mas sim em identidades plurais e multifacetadas, nas diversas características que individualizam as pessoas, as quais são construídas a partir das vivências e das historicidades de cada um e de cada uma no decorrer da vida.

Entre as identidades que compõem a estrutura humana, é possível averiguar que a esfera das sexualidades é sensível e tacitamente invisibilizada nos debates acadêmicos e sociais, sendo essa concepção oriunda de fatores culturais e de poder que tem envolvido a maioria das relações humanas. O elemento sexual identitário é fundamental nas análises sociais, não podendo ser ignorado, pois é indispensável perceber a expressão identitária sexual, ou a sexualidade humana, como a conjunção dos conceitos de sexo biológico e gênero como reflexo social deste, também é fundamental se ter presente a identidade de gênero como percepção de pertencimento de seu corpo, como um espectro social condizente com sua anatomia ou não e a orientação afetivo sexual como o desejo pela intimidade com determinados indivíduos.

É evidente que todas as acepções citadas são estritamente reguladas por normas sociais que seguem padronizadas na heteronormatividade binária. Entretanto, isso não condiz com a diversidade de expressões das 
sexualidades humanas, as quais têm sido consideradas, por grande parcela da população e dos poderes constituídos, como uma transgressão do padrão heteronormativo, afetando, diretamente, os direitos humanos dessas pessoas. Embasado por uma análise hipotético-dedutiva e pela revisão bibliográfica de teorias voltadas para as categorias do reconhecimento e do direito fraterno, pretende-se refletir acerca da importância do reconhecimento identitário e das sexualidades em vista dos direitos humanos, apresentando-se as contribuições e as limitações do Direito Fraterno para esse tema. Para atingir o objetivo exposto, o artigo iniciará com uma abordagem acerca de teorias do reconhecimento identitário, relacionando-as com as sexualidades, perpassando por uma reflexão sobre o devido reconhecimento de identidades sexuais e de sua inclusão no contexto contemporâneo de Estados Democráticos, para, então, finalizar com uma análise das contribuições do Direito Fraterno em vista do reconhecimento das identidades sexuais.

\section{Teorias do Reconhecimento de Identidades e Sexualidades}

O tema envolvendo identidades e sexualidades encontra-se em voga na atualidade dada a importância dos debates recorrentes sobre direitos humanos, que ensejam um aprofundamento maior acerca do reconhecimento de pessoas que são tidas como diferentes dentro dos padrões sociais hegemônicos, como é o caso do exercício de sexualidades que não as heteronormativas, bem como quando se trata de direitos sexuais. Dentro desse contexto, Roger Raupp Rios (2007) defende a proteção dos direitos sexuais sob o resguardo dos direitos humanos, no que ele denomina direito democrático sexual, o qual envolve uma abordagem das sexualidades pelo Direito, considerando a inter-relação destas com a democracia, a cidadania, os direitos sexuais e os direitos humanos. Essa abordagem remete à exigência de que o corpo sexuado humano seja elevado a um status jurídico de sujeito de direitos e não meramente um objeto necessário de interferência médica, como no caso de pessoas trans. Apesar de algumas aprovações de normas no âmbito interacional e brasileiro, em razão principalmente da difusão de discursos sobre direitos sexuais e reprodutivos, a legislação protetiva da autonomia e a liberdade de exercício das 
sexualidades estão distantes de domínios importantes ou têm sua efetivação comprometida.

Entre os marcos documentais internacionais sobre os direitos sexuais, a cientista política estadunidense Rosalind Petchesky (1999) destaca o papel da Declaração de Viena e da Declaração sobre Violência contra a Mulher, as quais incluíram o termo sexual na linguagem dos direitos humanos, mas apenas se reportaram à questão da violência sexual e não, propriamente, à seara das sexualidades. Somente na Conferência Internacional sobre População e Desenvolvimento, de 1994, foi que as identidades sexuais receberam o reconhecimento a partir de um aspecto positivo da sociedade humana, ressaltando-se, aqui, que tal previsão materializou-se apenas na perspectiva da saúde sexual por meio de concepção atribuída pela Organização Mundial de Saúde e, excluindo do texto, por sua vez, a ideia de prazer sexual. Em 1995, na IV Conferência Mundial da Mulher, em Beijing, avançou na formulação de um conceito de direitos sexuais, como parte dos direitos humanos. Porém, vale destacar que a pressão de instituições internacionais, em especial, a Santa Sé, e os países em que a política anda de mãos dadas com a religião, foi responsável pela supressão das expressões sexuais e orientação sexual dos documentos finais das conferências internacionais e, por conseguinte, tal posicionamento resultou em uma grande campanha de difamação das expressões direitos sexuais e reprodutivos e gênero, numa perspectiva de manobra que visava associar esses termos a filias e a outras condutas sociais que a cultura hegemônica e religiosa condena ${ }^{1}$.

Corroborando com o debate acerca de sexualidades e direitos humanos, Rosalind Pollack Petchesky (1999) defende uma visão alterna-

\footnotetext{
1 A partir dessas intervenções, ativistas que buscavam a inclusão daqueles termos nos documentos internacionais passaram a moderar o uso dos termos ou suprimi-los completamente de seus discursos, com medo das represálias que poderiam sofrer, não apenas de defensores, mas também da população que incorporou o discurso preconceituoso na base de seu senso comum. Isso demonstra uma sexofobia social e o tratamento das sexualidades como tabu no meio social (PETCHESKY, 1999). A linguagem dos direitos humanos deveria ir além de apenas mencionar proteções contra abusos e discriminações; ela deveria reconhecer o corpo sexuado e suas implicações, tanto as reivindicações de autodeterminação quanto o prazer.
} 
tiva e positiva dos direitos sexuais, como direitos humanos, a partir de dois componentes integrais e interligados: um grupo de princípios éticos e uma gama de condições capacitantes, sem as quais é impossível obter mudanças reais. Os princípios éticos apregoados são: a diversidade sexual, o respeito às mais diversas expressões sexuais, superando a questão da mera tolerância; o reconhecimento e o respeito às diferentes formas de composição da família, além do modelo nuclear de marido, mulher e filhos; a saúde, como vida sexual segura e satisfatória na qual o prazer sexual é parte da saúde básica e do bem-estar do sujeito humano; a autonomia pessoal para tomar decisões no que se refere à tomada de decisões acerca do próprio corpo e de sua saúde e o último princípio vem a ser a equidade de gênero, que está intrinsecamente ligada à autonomia, uma vez que todas as normas sexuais de uma sociedade estão intrinsecamente ligadas ao código cultural de gênero e família, que, geralmente, impõe a submissão da vontade feminina à arbitrariedade masculina. As realizações desses princípios éticos dependem de condições capacitantes, ou seja, mudanças econômicas, sociais e estruturais nos Estados contemporâneos, capazes de assegurar os direitos e garantias fundamentais a todos os seres humanos, em especial os hipossuficientes, entre estes as pessoas marginalizadas em razão de sua sexualidade.

Para a proteção jurídica a elementos identitários, em especial, os atributos sexuais da identidade, é necessário que aquela estenda seu objeto de regulação alcançando "[...] identidades, condutas, preferências e orientações mais diversas, relacionadas com aquilo que socialmente se estabelece, em cada momento histórico" (RIOS, 2007, p. 23). Esse direito à livre expressão da sexualidade está intrinsecamente ligado aos padrões socioculturais; entretanto, para assegurar o devido reconhecimento a todos os sujeitos ele deve ir além de uma mera catalogação de identidades e práticas sexuais.

Viabilizar um direito democrático sexual pressupõe que ocorra o devido reconhecimento das identidades das pessoas, nos seus contextos socioculturais, mas principalmente, de seus componentes identitários sexuais. Para fundamentar a perspectiva do reconhecimento de identidades sexuais, serão abordadas, brevemente, algumas teorias que se ocupam em explicar esses processos. Nesse sentido, o filósofo e sociólogo alemão 
Jürgen Habermas (2002) apresenta o reconhecimento como uma ação comunicativa, em busca do consenso. Somente o consenso, como meta de diálogo, pode legitimar o reconhecimento. Para o autor, o mundo social não está submetido a leis objetivas puras. A organização e a intersubjetividade humana nos contextos culturais criam normas e valores inerentes à vida social. Esses valores são líquidos, mutáveis, suscetíveis à revisão e à transformação. Nesses processos de mudança, a crítica é fundamental nos sistemas comunicativos permeados pelas relações de poder, para que sejam desmistificados os essencialismos identitários e, aflore um diálogo rumo ao consenso, que resultaria no reconhecimento do outro. Habermas (2002) destaca o reconhecimento intersubjetivo mútuo entre os sujeitos de direitos, sendo esse um dos alicerces do direito contemporâneo, responsável por assegurar a integridade dos sujeitos envolvidos².

Diante da teoria da ação comunicativa de Habermas, é preciso ter presente que, nem sempre o diálogo em busca do consenso é algo atingível. Muitas vezes, as diferenças geraram tantas desigualdades que um diálogo proporcional não é realizável. Pode-se perceber essa dificuldade no caso das identidades de sexualidades não heteronormativas que são constantemente afastadas de possíveis diálogos. Um desses casos ocorre no próprio Congresso Nacional que, na atualidade, possui um Projeto de Lei tramitando, denominado Estatuto da Família, o qual deixa claro que a única forma de família admissível é a formada por um homem, uma mulher, filhos e filhas. Agrupamentos fora desse padrão não poderão ser

${ }^{2} \mathrm{O}$ reconhecimento público pleno das identidades decorre do respeito, em especial, o respeito à identidade inconfundível de cada sujeito e as suas práticas culturais. Para o autor, o reconhecimento de identidades coletivas deve ser acompanhado de igualdades de direitos para todas as formas de vida culturais, buscando-se, acima de tudo, garantir a sobrevivência e a integridade dessas coletividades, quais podem ser formadas com base em diversos traços identitários, entre eles, a característica sexual da identidade. Isso somente é possível em um Estado democrático de direito, quando há presença de direitos coletivos assegurados pelo devido reconhecimento dessas identidades. Seguindo a mesma lógica de Habermas, Alan Tourraine (2009) defende o reconhecimento mútuo a partir do diálogo. Para o autor, objetiva-se evitar conflitos resultantes de choques culturais no processo de reconhecimento. Cada indivíduo deve respeitar as diferenças para conseguir demarcar seu status como sujeito social, sendo que é impossível uma convivência pacífica sem um diálogo capaz de abordar a diferença entre os indivíduos e as coletividades. 
considerados uma família, o que afronta a própria Constituição Federal de 1988, que já sofreu uma mutação constitucional no que se refere a esse tema, a partir da decisão do Supremo Tribunal Federal, quanto à adoção de crianças por casais homossexuais (Ação Direta de Inconstitucionalidade n. 4.277 e Ação de Descumprimento de Preceito Fundamental n. 132). Assim sendo, considera-se o diálogo e a ação comunicativa elementos importantes das interações humanas, mas nem sempre suficientes diante de relações de desigualdade.

Por sua vez, Axel Honneth (2003), que foi assessor direto de Habermas, discorda disso, apresentando o conflito como fator central na busca por reconhecimento e não o consenso. Em sua obra Luta por reconhecimento, o autor aborda reconhecimento identitário como elemento fundamental na construção e na interação das subjetividades das relações sociais da vida humana. Para o autor, nos processos de construção identitária ocorrem interiorizações do reconhecimento social, ou seja, o sujeito percebe não só sua identidade, mas a de terceiros indivíduos, a partir de modelos sociais hegemônicos. A luta por reconhecimento inicia-se a partir de um conflito: "[...] a experiência de desrespeito social pode motivar um sujeito a entrar numa luta ou num conflito prático [...]" (HONNETH, 2003, p. 219-220), como é o caso das pessoas homossexuais e/ou trans, sendo importante o autoconhecimento que gera a consciência do desrespeito e da violação de direitos humanos que assola essa pessoa. Frente a isso, as pessoas buscarão o reconhecimento a partir da reciprocidade de outros, nesse caso, terceiros indivíduos, a sociedade e o próprio Estado ${ }^{3}$.

\footnotetext{
${ }^{3} \mathrm{Na}$ percepção de Honneth (2003), há três esferas necessárias de reconhecimento intersubjetivo que são: a) A esfera do amor, que abrange o reconhecimento a partir do plano afetivo, de cuidado com o próximo e exprime-se na autoconfiança, enquanto devida forma de reconhecimento. Nesse sentido, é importante trazer à baila reflexões de Zygmunt Bauman (2004, p. 98): "Amar o próximo pode exigir um salto de fé. O resultado, porém, é o ato fundador da humanidade". Caracteriza-se, assim, a passagem das relações interpessoais da esfera instintiva para o campo da moralidade, no qual o amor e a esperança de ser amado é o caminho para o reconhecimento. O amor "[...] evoca o desejo do próximo de ter reconhecida, admitida e confirmada a sua dignidade de portar um valor singular, insubstituível e não descartável" (BAUMAN, 2004, p. 101); b) A sfera do direito, que se apresenta como elemento regulador de direitos e deveres. Nesse sentido, Rosângela Angelin destaca que "[...] a relação jurídica parte das relações de amor,
} 
A batalha pelo reconhecimento recíproco dos sujeitos e de suas identidades constitui os elementos essenciais para o surgimento e o estabelecimento de mecanismos capazes de assegurar aportes jurídicos de liberdade de indivíduos e grupos e, por consequência, permitir o progresso social e a inclusão de identidades marginalizadas na sociedade ${ }^{4}$.

A socióloga feminista Nancy Fraser (2006) também se ocupa de tratar da temática do reconhecimento, entretanto, seguindo um raciocínio embasado na necessidade de redistribuição econômica, como um elemento essencial para que haja o reconhecimento. Para a autora, reconhecimento e redistribuição são categorias essenciais para compreender os paradigmas da justiça socioeconômica e da justiça cultural ou simbólica, situação que abarca também os direitos sexuais. Na seara da redistribuição de renda, a análise ocorre no panorama das estruturas econômicas da sociedade em que as situações de exploração, de marginalização e de privação de condições materiais essenciais de pessoas cuja sexualidade não se encontra nos padrões heteronormativos; por isso, são necessárias ações afirmativas para romper com o quadro de injustiças. Para Fraser (2006), quando houver redistribuição econômica, automaticamente as pessoas modificarão seu status social, passando a ser reconhecidas pela sociedade e possibilitando paridade na participação de instâncias do Estado ${ }^{5}$.

porque nas relações de amor existem duas partes que realizam inteiração e, portanto, precisam de regras. As pessoas só podem perceber que são portadoras de direitos, quando sabem que existem obrigações em face do outro" (ANGELIN, 2014, p. 455); c) A esfera da solidariedade, em que o reconhecimento alcança o indivíduo e suas peculiaridades pelo tratamento sem discriminação, traduzindo-se na autoestima e na interação social, proporcionando espaços em que as pessoas, reciprocamente, se interessam pelos modos de vida diferentes dos seus, pois, nesse contexto, nutrem sentimentos de estima, sendo esse um fator importante para uma boa convivência em sociedade.

${ }^{4}$ Embora a teoria de Honneth apresente elementos importantes e fundamentais para o reconhecimento e a inclusão social, a implicância da reciprocidade para que haja o reconhecimento, impõe limitações à teoria: e se o outro não quiser reconhecer, o reconhecimento não estaria comprometido?

${ }^{5}$ Aparentemente antagônicos, os conceitos de redistribuição de renda e reconhecimento indentitário possuem um ideal de complementariedade, situação que colocou Axel Honneth e Nancy Fraser (2003) em diálogo na construção da obra Redistribuition or recognition? a political-philosofical exchange, a qual aborda essa questão. Constitui-se um dilema a relação entre os dois conceitos, pois o reconhecimento tende a produzir 
Outra teoria bastante utilizada para os debates sobre reconhecimento identitário envolve estudos do filósofo contemporâneo Charles Taylor (1998). Para ele, o reconhecimento advém da transição do ideal de honra para o ideal de dignidade, como elemento de diferenciação dos sujeitos humanos. Assim, as concepções de classes sociais hierarquizadas se afastam das relações humanas. As identidades se tornaram as premissas básicas dos indivíduos, e seu reconhecimento na vida na sociedade democrática, determina a necessidade de uma política do reconhecimento, a fim de assegurar o respeito a todas as expressões humanas, principalmente quando envolvem identificações culturais, em especial, as sexualidades. Nessa lógica, o autor ensina que

[...] a democracia introduziu a política de reconhecimento igualitário, que tem assumido várias formas ao longo dos anos, e que regressou agora sob a forma de exigências de um estatuto igual para as diversas culturas e para os sexos. (TAYLOR, 1998, p. 48)

Para Taylor (1988), a compreensão das identidades individuais propiciou a autonomia da vontade sobre as identidades dos sujeitos a partir do ideal de autenticidade. Assim, a subjetividade vivenciada no interior das pessoas ganha destaque na sua percepção social, passando-se a compreender o reconhecimento próprio e mútuo. A autenticidade aplica-se em dois níveis, nas relações interpessoais e nas relações entre culturas, buscando permitir que os sujeitos se desenvolvam livremente; situação essa que entra em conflito com os modelos sociais de comportamentos preestabelecidos e hegemônicos, fazendo com que os efeitos do reconhecimento das pessoas com identidades sexuais diferentes dos padrões tidos

diferenciações e particularidades ao passo que a redistribuição pende a enfraquecer estas. Ao mesmo tempo em que medidas de reconhecimento condenam ações universalistas, pontuais e igualitárias, as medidas redistributivas as encorajam. Ambos os conceitos também se complementam uma vez que os remédios de reconhecimento pressupõem uma subjacente concepção de redistribuição e vice-versa. A conjugação e a ênfase entre essas medidas dependem do caso específico. Não basta a aplicação de uma ou outra formulação teórica para o devido tratamento das sexualidades na perspectiva jurídica, mas é necessário verificar as dinâmicas próprias para o contexto sociocultural. 
como normativos sofram estigmatizações sociais, mesmo que legislações versem sobre a inclusão.

\section{O Devido Reconhecimento de Identidades Sexuais no Processo de Inclusão Social}

É a partir do reconhecimento, seja ele correto ou não, que os sujeitos sociais constroem suas identificações com identidades sociais coletivas e seus sentimentos de pertença à sociedade. Taylor (1998) defende uma política de dignidade universal, entretanto, essa somente é possível quando há respeito entre os sujeitos envolvidos e suas diferenças, na criação de um sistema social caracterizado pela igualdade, reciprocidade e unidade de propósito. Diante do fato de todos os indivíduos possuírem uma honra inerente a sua condição humana, Taylor desta que, assim, todos e todas teriam igual dignidade, pelo simples fato da humanidade comum, entre eles. Por respeitar a singularidade de cada indivíduo, o igual valor das diferenças se torna a base para o reconhecimento positivo pautado na dignidade, nos moldes que defendem Honneth e Taylor. O devido reconhecimento das identidades na esfera jurídica enseja a categoria dos direitos de personalidade morais (BITTAR, 2015). Para tanto, o reconhecimento das identidades comporta os elementos individualizadores, os quais, no caso das pessoas trans, inseridas na realidade brasileira, se refletem principalmente em questões atinentes ao Registro Público, em especial, ao nome e ao designativo do sexo registral. Nesse mesmo sentido, as sexualidades, enquanto elementos da identidade se enquadram nos direitos de personalidade (DINIZ, 2001). Essencialmente, para o devido reconhecimento das identidades trans no Brasil, o reflexo da possibilidade material de mudança corporal deve ser correspondido pela adequação do Registro Público da pessoa, e essa alteração deve ser refletida e respeitada no meio social ${ }^{6}$.

${ }^{6}$ Cabe ressaltar que até o momento da submissão do presente artigo, ainda não foi publicada no Diário Oficial da União a decisão da Ação Direta de Inconstitucionalidade (ADI) n. 4.275 , de 2009, a qual versa sobre a retificação registral do nome de pessoas trans. De acordo com o julgamento realizado no dia $1^{\circ}$ de março de 2018 , ficou resguardado o direito de pessoas trans retificarem seu registro civil sem a necessidade de cirurgia de 
Em contrapartida e, seguindo o exposto por Honneth (2003), há o reconhecimento negativo ou pelo reconhecimento equivocado, apregoado por Taylor (1998), sendo situações manifestadas na forma de ações embasadas no preconceito e na discriminação. Roger Raupp Rios (2009) faz uma distinção entre os conceitos preconceito e discriminação. Preconceito é entendido na qualidade de percepções mentais negativas de identidades individuais e coletivas, enquanto o termo discriminação remete à materialização do preconceito, ou seja, remete à prática de atitudes arbitrárias, omissivas ou comissivas que implicam no desrespeito de um sujeito ou de uma coletividade. Ao passo que o primeiro termo é típico da academia, em especial, da área da psicologia e das ciências sociais, o último é amplamente incorporado nos discursos jurídicos.

Juno Dawnson (2015) destaca que o grande problema do reconhecimento negativo se encontra em razão da estigmatização e da estereotipificação das identidades, com criação de identidades virtuais essencializadas. Destaca-se que é muito mais fácil discriminar alguém, principalmente em discursos nos meios social, quando se tem em mente não um ser humano, mas sim um estereótipo ${ }^{7}$. Para Charles Taylor (1998), o não reconhecimento político e social ou o reconhecimento equivocado dos indivíduos e das coletividades, a partir do devido tratamento de suas identidades pautadas nas diferenças, implica em extrema violação dos direitos humanos ${ }^{8}$. Outros dois termos importantes de serem diferen-

redesignação sexual, de laudo psiquiátrico ou mesmo de um processo judicial. A decisão é um marco no reconhecimento da liberdade e da autonomia das identidades sexuais, em especial a de pessoas trans. Resta aguardar como será implementada essa decisão no ordenamento jurídico brasileiro, e a regulamentação do processo administrativo dos cartórios de registro para que se procedam as retificações, mediante futura resolução do Conselho Nacional de Justiça.

${ }^{7}$ Importante ressaltar que, nesse contexto, uma forma de evolução é desmistificar esses estereótipos e isso pode ocorrer de diversas formas; uma delas, quem sabe a mais eficaz, é pelo contato próximo de pessoas estereotipadas, conhecendo e vivenciando a opressão e o menosprezo sofridos por elas. Como já destacava Honneth, é preciso do outro para que haja o reconhecimento e quando este, por meio de um contato mais próximo, se solidariza, a possibilidade do reconhecimento identitário será mais efetiva.

${ }^{8}$ Isso em razão das repercussões negativas que afetam a vida das pessoas. Essa forma de reconhecimento negativo desclassifica e estigmatiza os sujeitos, além de segregar os diferentes no meio social. 
ciados no debate acerca do reconhecimento equívoco das identidades são vulnerabilidade e suscetibilidade. Nesse sentido, Miguel Kottow (2012) afirma que a humanidade, em si, está em constante estado de vulnerabilidade, termo este entendido como a possibilidade de sujeição das pessoas ao dano; ao passo que a suscetibilidade é a situação do dano instalado e perpetuado. Então, diante do reconhecimento de identidades sexuais, por exemplo, o não reconhecimento dos efeitos civis do processo de redesignação sexual de pessoas trans, faz com que esses indivíduos, por não terem as mínimas condições sociais para atender às suas necessidades básicas, passem da situação de vulnerabilidade, considerada condição universal da espécie humana, para uma condição seletiva e profunda, que é uma variável vulneração na qual ocorre a privação de direitos básicos e intrínsecos à vida de qualquer pessoa.

A situação de vulneração das pessoas trans remete à forma de reconhecimento negativo e equivocado, podendo ser demonstrada por meio da figura jurídica romana do Homo Sacer. Conforme leciona o filósofo italiano Giorgio Agamben (2003), a figura do homem sacro ou homo sacer refere-se aos sujeitos expulsos da vida em sociedade pela prática de um crime, marginalizados nas relações sociais, sendo que quem viesse a cometer qualquer violência contra eles não seria punido pelos seus atos. Analisando, a partir da atualidade contemporânea, pode-se perceber que isso ocorre não apenas pelo desrespeito à identidade de muitas pessoas que são diferentes ao padrão normal de seres humanos, mas, também, pelo descaso do poder público, em geral, e pela falta de políticas públicas. No caso das pessoas trans, isso significa deixá-las à mercê de outros membros da sociedade que promovem agressões em diferentes patamares, ressaltando-se, ainda, que aqueles na buscam do auxílio no poder público, nos devidos órgãos, poderão sofrer outros incidentes de violência psicológica ou simbólica. Outro obstáculo para o reconhecimento público pleno de minorias marginalizadas, como o de sujeitos com orientação sexual diferente da heterossexual, é a impregnação ética da comunidade jurídica e do processo democrático para efetivação de direitos fundamentais; os quais possibilitam a extremistas embasados em discursos fundamentalistas discriminatórios ensejar o cerceamento de direitos com base na vontade da maioria (HABERMAS, 2002). 
Corroborando com o debate, José Francisco Dias da Costa Lyra (2013, p. 47) pondera que "[...] os excluídos não são investidos de direitos, sendo a população 'integrada' na condição de obrigada, acusada, e, não na condição de titular de direitos fundamentais, que não estão disponíveis aos grupos excluídos". Evidencia-se uma exclusão de natureza jurídica dos indivíduos marginalizados para a sociedade, manifesta por uma deslegitimação do Estado de Direito perante as categorias de sujeitos não incluídos no metacódigo de inclusão/exclusão inerente a democracia. E, em razão desse desrespeito com os diferentes, é preciso estabelecer uma busca da coerção jurídica para garantir direitos identitários, em especial quanto ao exercício da característica sexual das identidades.

Eis, então, que se evidencia, ainda mais, a biopolítica, vista como a politização das interações do mundo fático, na qual os mecanismos e os cálculos do poder estatal incluem as relações da vida natural, objetivando disciplinar o indivíduo, combatendo todas as anormalidades e patologias e não o tratando como alguém que transcenda a mera taxação, sem considerar o referencial histórico de cada pessoa. É importante se ter presente que, na sociedade contemporânea, já se iniciou um processo de mudança no tratamento dos excluídos, conforme pondera Lyra (2013, p. 40): "A velha prerrogativa de isentar e excluir da biopolítica estatal soberana o homo sacer foi revisada". Assim, nota-se uma preocupação de alguns setores com a inclusão dos indivíduos marginalizados, mas o poder pós-panóptico estatal ainda objetiva a manutenção destes fora dos meios sociais devidos, em vez de buscar a sua inclusão. Entretanto, ainda são necessários outros meios de garantir o reconhecimento da identidade sexuais, tendo em vista os fins da biopolítica e sua íntima relação entre o poder e o saber, é evidente que novas formas de disciplina e controle social (LYRA, 2013), por parte do Estado, devem atender aos anseios de inclusão e respeito aos diferentes.

Os direitos atinentes às sexualidades, como forma de coibir discriminações, podem ser entendidos como desdobramentos dos direitos gerais de "[...] privacidade liberdade, intimidade, livre desenvolvimento da personalidade, igualdade" (RIOS, 2001, p. 31). Nessa perspectiva, a conotação pejorativa que se tem das sexualidades que não se enquadram no padrão heteronormativo de gêneros binários, geralmente é afastada. 
Entretanto, isso acaba por criar um debate acadêmico-profissional que se ocupa das questões sobre as sexualidades no meio jurídico, abordando se esses são extensões de direitos iguais, aplicados a todas as expressões sexuais, ou direitos especiais, na forma de desenvolvimento de legislação ordinária contra a discriminação. Essa dicotomia de entendimento jurídico serve para tachar de maneira depreciativa a proteção às diferenças, como ocorre em inflamados discursos essencializantes das identidades, nas esferas de convivência social (RIOS, 2007, p. 31).

$\mathrm{O}$ direito democrático sexual não pode ser restringido a esferas de sociabilidade específicas, sob pena de converter-se em um instrumento inútil contra a discriminação. Para que o potencial protetor dos direitos sexuais seja alcançado, ele deve contemplar tanto o âmbito público quanto o âmbito privado da vida em sociedade (RIOS, 2007). O plano privado, em especial a família, não pode tornar-se um refúgio para a proliferação de ideais machistas heteronormativas, pois implicaria a desvalorização cultural das diferenças. Assim, os direitos humanos e fundamentais aplicados às sexualidades necessita ultrapassar a barreira do campo privado individual para abordagens realmente preocupadas com a inclusão de todos na vida em sociedade.

Rosalind Petchesky (1999, p. 34) pondera que, “Apesar de estar convencida de que as construções afirmativas dos direitos humanos necessitam mais a nossa atenção, como intelectuais e ativistas, o enfoque 'liberatório' dado aos direitos sexuais apresenta seus próprios dilemas". Entre esses dilemas estão as questões de que ao tentar ser uma categoria universal e inclusiva, os direitos sexuais podem ser uma linguagem totalizante e excludente ao criarem identidades virtuais essencializadas. Entretanto, o atual quase silêncio acerca dos direitos sexuais nos documentos jurídicos é algo que merece ser reavaliado no contexto para a concretização da dignidade humana e da convivência plena, razão pela qual se insere o debate acerca do Direito Fraterno e da sua contribuição para o reconhecimento das identidades sexuais. 


\section{O Pensar e o (Re) Pensar o Direito pela Fraternidade}

Era 1976, durante o período da Ditadura Militar, quando Waldirene, após ter sido levada coercitivamente por dois homens ao Instituto Médico Legal, foi constrangida a se despir, permaneu apenas com suas sandálias e foi fotografada. Cada flash revelou uma jovem loura, de 30 anos, com $1 \mathrm{~m}, 72 \mathrm{~cm}$ de altura, cujos olhos miravam o chão, com os braços colados ao corpo e as pernas cerradas na inocente tentativa de se proteger da exposição. Tão logo a sessão de fotos terminou, Waldirene foi submetida a um exame ginecológico, com a introdução de um espéculo de metal em seu corpo para registrar o cumprimento e a largura do canal vaginal. O objetivo era atestar se Waldirene era mulher, pois seu nome registral era Waldir Nogueira (GLOBO.COM, 2018). Cinco anos antes, Waldirene foi submetida a uma cirurgia de mudança de sexo genital, realizada pelo médico Roberto Farina, na cidade de São Paulo. Antes da operação, Waldirene foi acompanhada por dois anos por uma equipe interdisciplinar, que a identificou como transexual e, por conseguinte, possibilitou a cirurgia. No entanto, o Ministério Público de São Paulo, ao tomar conhecimento da operação de mudança de sexo, denunciou o cirurgião por lesão corporal gravíssima, desconsiderando o consentimento da vítima e pautando-se de que os órgãos genitais masculinos se constituíam em bem físico tutelado pelo Estado, cujas características eram inalienabilidade e irrenunciabilidade (GLOBO.COM, 2018).

No pedido de instauração do inquérito policial, o promotor de justiça, Luiz de Mello Kujawski, sustentou que ao serem realizadas tais cirurgias,

[...] o que consegue é a criação de eunucos estilizados, para melhor aprazimento de suas lastimáveis perversões sexuais e, também, dos devassos que neles se satisfazem. Tais indivíduos, portanto, não são transformados em mulheres, e sim em verdadeiros monstros. (GLOBO.COM, 2018)

Em 1978, a magistrado que julgou o caso concluiu que o paciente, no caso Waldirene, deveria ter sido "[...] submetido a tratamento psi- 
canalítico de longa duração como tentativa de cura [...]", condenando o médico responsável pela cirurgia genital a dois anos de reclusão pela prática de lesão corporal gravíssima. Em segunda instância, a sentença de primeiro grau foi anulada, não sem antes a acusação registrar nos autos que ao se admitir que "[...] ele (Waldir) possa oferecer sua neovagina a homens, então somos forçados a concluir que agora ele é uma prostituta [...]", adicionando, ainda, que mesmo

[...] mutilado, Waldir continuará sendo o que sempre foi, ou seja, um homem que mantém relações sexuais com outros homens. Mas a prática de relações sexuais entre pessoas do mesmo sexo será sempre uma aberração, tanto à natureza como à lei. (GLOBO. COM, 2018)

Em 2018, 20 anos posteriores à autorização pelo Conselho Federal de Medicina para a realização de cirurgias de mudanças de sexo em transexuais, Waldirene, com 71 anos, continua a laborar como manicure, profíssão da época da cirurgia, e ainda carrega consigo estigmas e rótulos a ela atribuídos. Da primeira cirurgia à época atual, gerações se sucederam, ciência, medicina e tecnologia avançaram rapidamente e, embora comportamentos e culturas tenham evoluído, ainda se encontram as relações sociais e as próprias identidades pautadas no patriarcalismo e nos costumes do século anterior. Tal estagnação do tecido social é tão visível que na reportagem que relata a história de Waldirene e sua luta para ser reconhecida, é possível observar comentários que enaltecem as afirmações do promotor de justiça ou, ainda, rechaçam qualquer possibilidade de reconhecimento da identidade sexual, conforme segue: "Milton José - procurador Luiz de Mello Kujawski esse me representa!" e "Nilson Rio40 - Um homem, no máximo, será uma boa imitação de mulher, mas jamais será uma mulher, pois nunca terá útero e ou mesmo um clitóris. Essas pessoas preferem se abdicar da sua sexualidade a se aceitarem... Um dia, esta loucura vai passar" (GLOBO.COM, 2018)

Como se observa, a positivação da proteção à identidade sexual evoluiu significativamente, porém não garante o seu reconhecimento pela sociedade e pelo Estado. Defende-se, portanto, o modelo de sociedade 
civil democrática na qual os cidadãos que a habitam não sejam consumidores dos serviços do Estado, mas defensores de direitos individuais e coletivos. $\mathrm{O}$ avanço requer cidadãos democráticos ativos, responsáveis, membros comprometidos de grupos e comunidade, dispostos a explorar um lugar que seja realmente para todos, compartilhado por todos (BARBER, 2000). Há, nesse sentido, a contribuição do Direito Fraterno, cujo escopo é pensar o direito em relação à civitas maximas e não em relação às pequenas pátrias dos Estados, coincidindo com o espaço de reflexão ligado aos Direitos Humanos, consciente de que a humanidade é o lugar comum e somente em seu interior pode ser pensado o reconhecimento e a tutela. É neste sentido que Resta ressalta que "Os Direitos Humanos são aqueles direitos que somente podem ser ameaçados pela própria humanidade, mas que não podem encontrar vigor, também aqui, senão graças à própria humanidade" (RESTA, 2004, p. 13).

A fraternidade se revela como a grande promessa da Revolução Francesa ${ }^{9}$, porém, esquecida em face da igualdade e da liberdade, que tão pouco são efetivadas para todas as pessoas. Ao retornar, com a mesma força, ela possibilita que seja refletido o egoísmo oculto nos globalismos arrogantes e permite o crescimento de um processo de autorresponsabilização, pois pressupõe-se que o reconhecimento do compartilhamento se liberte da rivalidade destrutiva típica do modelo vigente irmãos-inimigos, cujos reflexos se visualizam, no caso em tela, na perpetuação da discriminação e na opressão a pessoas trans. O vocábulo fraternidade, de origem do latim frater, significa irmão, e no seu derivado fraternitas, fraternitatis e fraternitate. É um substantivo feminino, cujo significado é apresentado em quatro sentidos: por parentesco de irmãos ou irmãs; união fraternal; amor ao próximo; e boa inteligência entre os homens, harmonia. Dos significados obtidos, vislumbra-se a fraternidade como um bom e harmônico convívio entre os seres humanos, na união de ideias e esforços e na boa convivência em comunidade. "Daí inicia-se uma primeira ideia do que venha a ser o Direito Fraterno: é um direito que é para todos e que é aceito e/ou proposto por todos" (STURZA; MARTINI, 2016, p. 995).

\footnotetext{
${ }^{9}$ The proposal of meta-theory of Fraternal Law is to understand how the conception of Enlightenment Revolution can be implemented and analyzed in the present day, although not by its presence but by its absence (MARTINI, 2018).
} 
O debate sobre a identidade sexual e seu reconhecimento como pauta dos direitos humanos, de forma intrínseca apresenta as exigências do Direito Fraterno o qual é pautado nos fundamentos da própria Constituição Federal de 1988, no inciso IV do artigo $3^{\circ}$, que tutela as manifestações da diversidade sexual a partir do princípio da diferença. Baseados nesse instituto jurídico constitucional, propulsor dos direitos humanos é que o Poder Judiciário, como já mencionado, se pautou para efetivar tal premissa, quando julga a ADI n. 4.277 e a ADPF n. 132. O princípio da fraternidade carrega a ideia originária da dignidade, pois a fraternidade integra o reconhecimento da condição humana e, uma vez praticado o ato fraterno, também se pratica um ato digno. Desse modo, compreende-se que

[...] diante do conteúdo jurídico da fraternidade, os intérpretes do direito devem atualizar o sentido de comunidade política e democrática integrado ao aspecto específico da dignidade humana no viés constitucional. (RESTA; JABORANDY; MARTINI, 2017, p. 99)

Verifica-se, nesse sentido, a importância da fraternidade por apostar no desempenho de um papel político na interpretação e na transformação do mundo real, revelando um valor heurístico e uma eficácia prática. Se eliminada no cenário social, a fraternidade pode ser resgatada como meio de possibilitar o reconhecimento do outro e de sua alteridade, o que justamente carece a identidade sexual, como já abordado, anteriormente.

Envolvendo o debate acerca da alteridade, Luis Alberto Warat chama a atenção para o lugar que os corpos e as identidades assumem numa sociedade, uma vez que essa sociedade impõe "[...] a censura aos corpos que sentem. São as idéias que determinam as condições para que os outros nos amem, sejam indiferentes ou nos tenham ódio" (WARAT, 2004, p. 28). Percebe-se, por conseguinte, que dadas condições, alicerçadas por uma racionalidade sem sentimentos, dificultam a reciprocidade exigida num contexto de reconhecimento, podem, inclusive, reproduzir preconceitos, manifestações de ódio e exclusão social. Por tais razões é que os 
debates sobre alteridade envolvem a sensibilidade de colocar-se ao lado do outro para compreender suas vivências e, a partir disso, se construir uma ética do reconhecimento do outro.

Por tais motivos que se faz mister que o direito ser (re)pensado a partir das premissas da fraternidade, afastando o que Luiz Alberto Warat (1996) denomina de racionalidade centrada binária e hegemônica, que em nada contribui para a abertura do pensamento e da reflexão jurídica em prol dos direitos humanos. O desafio para a sociedade e para o mundo jurídico é passar a olhar o outro a partir de outros parâmetros capazes de propiciar a humanização, sem se prender a normas fechadas e unificadoras de significados ${ }^{10}$. E, o Direito Fraterno oportuniza a abertura da fronteira da cidadania, desvelando a necessidade de respeito à diversidade de manifestação humana, como no caso a diversidade de identidades sexuais que requerem reconhecimento social e jurídico.

Nesse sentido, Francesco Rubino e Sandra Regina Martini (2018) destacam que a fraternidade se apresenta como uma condição de seres pertencente à mesma espécie, que apresentam vulnerabilidades e fragilidades, sendo, portanto, necessário que construam relações solidárias entre si, como um fundamento ético para todas as pessoas; assim poderão ir além dos limites políticos e lógicos da própria lei, num exercício paradoxal de promoção de uma ética comum. A sociedade fraterna aposta na própria humanidade, na existência de um bem comum, pois " [...] ele não se fundamenta em um ethnos que inclui e exclui, mas em uma comunidade, na qual as pessoas compartilham sem diferenças, porque respeitam todas as diferenças" (STURZA; MARTINI, 2016, p. 996). O Direito Fraterno trata-se de um direito jurado em conjunto por irmãos, homens e mulheres, os quais, em união, convencionam as regras basilares de sua convivência. Para tanto, a linguagem jurídica precisa estar ao alcance de todos, isto é, pertencer a todos (RESTA, 2004). Verifica-se, nessa ótica,

\footnotetext{
${ }^{10}$ La fiesta del pensamiento: lo impensado que nos fuerza a pensar, que llama a lo nuevo, renegando todo y cualquier tipo de ambición unificadora de los significados. De ninguna manera síntomas de impotência del pensamiento: es más bien lo que potencia, lo que obliga al pensador, com la fuerza de una pasión, a plantearse problemas y no dar soluciones. Un pensamiento que intenta que el hombre pueda volverse digno de lo que sucede, de lo impensable, del azar: uma ética del pensamiento (WARAT, 1996, p. 74-75).
} 
que "[...] a fraternidade expande o imaginário da tradição moderna individualista ao direcionar o aspecto intersubjetivo da consciência fraterna na esfera do reconhecimento social" (RESTA; JABORANDY; MARTINI, 2017, p. 100).

Defende-se aqui um Direito altruísta, humanista, fraterno, um paradigma jurídico da razão sensível. O Direito, fundamentado na fraternidade, revela-se em um mecanismo de promoção dos direitos humanos - "[...] os Direitos Humanos foram e continuam a ser o grande motor da regeneração do Direito. Apesar de todas as suas (talvez inevitáveis) deformações e incompreensões [...]" (CUNHA, 2016, p. 27) -, cujo objeto é o lugar comum, fundamentado na amizade, na ruptura da busca pela identidade e no pacto pela paz (STURZA; ROCHA, 2016).

Para Resta (2004, p. 31)

[...] a amizade reaparece nos sistemas sociais como diferença entre interação de identidades individuais, que se escolhem e orientam a comunicação voluntariamente, e as relações burocráticas e heterodirecionadas dos mecanismos dos grandes sistemas funcionais.

O olhar de Resta é, antes de tudo, um olhar para os direitos humanos. Não há espaço para etnocentrismo e, por isso, o Direito Fraterno é cosmopolita (pois reporta ao cósmico, ao valor universal dos direitos humanos, e não à lógica mercantilista); não é violento, pois se pauta na mediação (ideia de jurisdição mínima); é inclusivo, visto que escolhe os direitos fundamentais e define o acesso universalmente compartilhado, onde todos podem gozar, e não somente uma minoria (RESTA, 2004).

Ademais, o Direito Fraterno traz em si um resgate de princípios iluminista, baseados na fraternidade:

Esta nova proposta, na verdade, aponta para uma nova 'luz', uma nova possibilidade de integração entre povos e nações, integração esta fundamentada no cosmopolitismo, onde as necessidades vitais são suprimidas pelo pacto jurado conjuntamente. (STURZA; ROCHA, 2016) 
Verifica-se, ademais, que ser amigo da humanidade é participar dos destinos das pessoas, ser movido por uma ideia, ter respeito por qualquer outro e por si mesmo, possuir sensibilidade, dever e responsabilidade; visto que a humanidade é termo inclusivo, é o lugar-comum das diferenças, pois contém, ao mesmo tempo, amizade e inimizade. Defende-se, desse modo, a ressignificação do Direito pela fraternidade, pois ela

[...] encaminha-se, portanto, para a realização de um processo mediador construtivo da interação comunicativa, agindo no enfrentamento dos conflitos sociais e culturais. (RESTA; JABORANDY; MARTINI, 2017, p. 101)

Justifica-se a abordagem da identidade sexual pela ótica do Direito Fraterno, pois um Direito sensível, humano e fundamentado na fraternidade exige o reconhecimento do amigo da humanidade, o qual "[...] endereça sua amizade a uma ideia, um projeto, no qual conta o respeito por qualquer outro, e, assim, por si mesmo.” (RESTA, 2004, p. 40). Trata-se da amizade pela humanidade, alicerçada na superação das ambivalências emotivas e na escolha do universalismo para a sobrevivência do todo. $\mathrm{O}$ amigo da humanidade compartilha o sentido da humanidade, sentindo-se parte dela, sem negar a existência do inimigo. Ao contrário, assume inteiramente o seu problema, não o seu descarte ou, ainda, sem colocá-lo à margem. $\mathrm{O}$ amigo da humanidade reconhece a identidade sexual e possibilita que as relações sociais sejam pautadas na defesa dos Direitos $\mathrm{Hu}-$ manos e da humanidade como lugar comum. O Direito Fraterno, portanto, possibilita uma ressignificação da comunidade e do interesse coletivo.

\section{Conclusão}

Abordar questões envolvendo identidades sexuais e seu reconhecimento social envolve, claramente, tratar da viabilidade de garantir e de reconhecer direitos humanos que estão sendo violados e/ou ameaçados. Nesse sentido, os direitos humanos importam, sobretudo, no reconhecimento da diversidade identitária das humanidades. Pensar em direitos humanos importa em adentrar na questão da alteridade, como foi apresen- 
tado no contexto das teorias sobre o reconhecimento, que envolve muito mais do que a ideia de se colocar no lugar do outro; o que é humanamente impossível, uma vez que cada ser é único e vivência as experiências de forma diversa. Alteridade remete à responsabilidade de se colocar ao lado destes sujeitos e, a partir disso, exercer uma convivência respeitosa com essas pessoas e suas diferenças.

A importância das identidades é representada no convívio social por meio das formas de seu reconhecimento. Portanto, o reconhecimento não pode estar pautado em essencialismo, mas no respeito inerente às pessoas e sua dignidade na acepção dos direitos humanos, bem como em condições materiais e econômicas que propiciem sua inclusão na sociedade. As sexualidades necessitam serem abordadas pela perspectiva jurídica e legislativa sobre a ótica dos direitos humanos, para que sejam assegurados o reconhecimento positivo e respeito para com as pessoas e seus corpos. Porém, a omissão legislativa a nível federal brasileiro, baseadas em orientações religiosas e preconceitos culturais, perpetua situações de reconhecimento negativo das identidades trans no meio social, principalmente na seara do aspecto moral dos direitos de personalidade, entre estes, o nome e o designativo sexual no registro público. As pessoas que assim se expressam buscam a tutela jurisdicional do Estado brasileiro para assegurar direitos identitários básicos, que constantemente são violados no cotidiano. Junto à omissão legislativa, muitos posicionamentos de parlamentares brasileiros têm demonstrado níveis de preconceito inadmissíveis diante de questões identitárias envolvendo homossexuais, pessoas trans e mulheres, o que afronta, claramente, preceitos constitucionais que versam sobre a não discriminação por sexo, preceito fundamental da Constituição Federal de 1988.

Nesse contexto, a teoria do Direito Fraterno, assim como as demais teorias sobre o reconhecimento aqui abordadas, por si só, não resolve o problema da violação de direitos humanos envolvendo questões de identidades sexuais; porém, não se pode negar que elas contribuem, de maneira específica e pontual, para a reflexão das realidades e para a promoção de espaços de alteridade, a fim de que o reconhecimento de identidades sexuais seja garantido nas sociedades plurais e nos ordenamentos jurídicos. Sobretudo, a proposta do Direito Fraterno é humanizar as relações 
sociais, demonstrando que, embora a individualidade seja importante na constituição do sujeito, é no contexto social e coletivo que elas se desenvolvem e são reconhecidas, ensejando, portanto, relações mais humanizadas e solidárias que respeitem o direito humano à diferença, inclusive, por parte do Estado.

\section{Referências}

AGAMBEN, Giorgio. Homo Sacer: o poder soberano e a vida I. Tradução Henrique Burigo. Belo Horizonte: Editora UFMG, 2002.

ANGELIN, Rosângela. Direitos humanos das mulheres e movimentos feministas nas sociedades multiculturais: uma leitura a partir da perspectiva teórica do reconhecimento e da redistribuição de gênero em Axel Honnet e Nancy Fraser. In: CONGRESSO INTERNACIONAL DA FACULDADES EST, 2, 2014, São Leopoldo. Anais [...] São Leopoldo: EST, 2014, p. 444-458. Disponível em: http://anais.est.edu.br/index.php/ congresso/article/viewFile/248/213. Acesso em: 29 abr. 2016.

BAUMAN, Zygmunt. Amor líquido: sobre a fragilidade dos laços humanos. Tradução de Carlos Alberto Medeiros. Rio de Janeiro: Zahar, 2004.

BITTAR, Carlos Alberto. Os direitos da personalidade. 8. ed. rev., aum. e mod. por Eduardo C. B. Bittar. São Paulo: Saraiva, 2015.

CUNHA, Paulo Ferreira da. Do Direito Fraterno Humanista: diálogos e vetores. Revista Brasileira de Estudos Jurídicos, [S.l.], v. 11, n. 1, p. 13-36, jan./jun. 2016.

DAWNSON, James. Este livro é gay, é hétero, e bi, e trans. Tradução Rafael Mantovani. São Paulo: Editora WMF Martins Fontes, 2015.

FRASER, Nancy. Da redistribuição ao reconhecimento? Dilemas da Justiça numa era "pós-socialista”. Cadernos de Campo, (São Paulo, 1991), São Paulo, v. 15, n. 15/16, p. 231-239, março, 2006.

HABERMAS, Jürgen. A inclusão do outro: estudo de teoria política. Tradução George Sperber e Paulo Astor Soethe. São Paulo: Loyola, 2002. 
HONNETH, Axel. Luta por reconhecimento: a gramática moral dos conflitos sociais. Tradução de Luiz Repa. São Paulo: Ed. 34, 2003.

HONNETH, Axel; FRASER, Nancy. Redistribuition or recognition? A political-philosofical exchange. Tradução Joel Golb, James Ingram, Christiane Wilke. London; New Yourk: Verso, 2003.

KOTTOW, Miguel. Vulnerabilidad entre derechos humanos y bioética. Relaciones tormentosas, conflictos insolutos. Derecho PUCP, Lima, n. 69, 25-44, janeiro, 2012. Disponível em: http://revistas.pucp.edu.pe/ index.php/derechopucp/article/view/4261. Acesso em: 8 jan. 2016.

LYRA, José Francisco Dias da Costa. O Estado na era da fluidez: homo sacer como expressão da biolitítica do direito penal imperial. In: HOMMERDING, Adalberto Narciso; ANGELIN, Rosângela. (Org.).

Diálogo e entendimento: direito e multiculturalismo \& políticas de cidadania e resoluções de conflito. Rio de Janeiro: LMJ Mundo Jurídico, 2013. v. 5. p. 24-58.

\section{MARTINI, Sandra Regina. Right to Health in the Brics' Context:} distances and proximities. [2018]. Disponível em: http://www. comparazionedirittocivile.it/prova/files/martini_health.pdf. Acesso em: 28 mar. 2018.

PETCHESKY, Rosalind Pollack. Direitos sexuais: um novo conceito na prática política internacional. In: BARBOSA, Maria Regina; PARKER, Richard [Org.]. Sexualidades pelo avesso: direitos, identidades e poder. Rio de Janeiro: IMS/UERJ; São Paulo: Ed. 34, 1999. p. 15-38.

RESTA, Eligio. Direito Fraterno. Santa Cruz do Sul: EDUNISC, 2004. RESTA, Eligio; JABORANDY, Clara Cardoso Machado; MARTINI, Sandra Regina. Direito e Fraternidade: a dignidade humana como fundamento. Revista do Direito, Santa Cruz do Sul, v. 3, n. 53, p. 92 103, set./dez., 2017.

RIOS, Roger Raupp. Notas para o desenvolvimento de um direito democrático da sexualidade. In: . Em defesa dos direitos sexuais. Porto Alegre: Livraria do Advogado Editora, 2007. p. 13-38. 
. Homofobia na perspectiva dos Direitos Humanos e

no contexto dos estudos sobre preconceito e discriminação. In: JUNQUEIRA, Rogério Diniz. (Org.). Diversidade sexual na educação: problematizações sobre a homofobia nas escolas. Brasília: Ministério da Educação, Secretaria de Educação Continuada, Alfabetização e Diversidade, UNESCO, 2009.

ROSSI, Amanda. Monstro, prostituta, bichinha: como a Justiça condenou a $1^{\mathrm{a}}$ cirurgia de mudança de sexo do Brasil e sentenciou médico à prisão. [2018]. Disponível em: https://g1.globo.com/bemestar/ noticia/monstro-prostituta-bichinha-como-a-justica-condenou-a-1acirurgia-de-mudanca-de-sexo-do-brasil-e-sentenciou-medico-a-prisao. ghtml . Acesso em: 28 mar. 2018.

RUBINO, Francesco; MARTINI, Sandra Regina. Il Diritto Fraterno e il parodosso dei beni comuni dell'umanitá. Revista Direito e Justiça: Reflexões Sociojurídicas, Santo Ângelo, v. 18, n. 31, p. 125-144, maio/ ago. 2018.

STURZA, Janaina Machado; ROCHA, Claudine Rodembusch. Direito e Fraternidade:

paradigmas para a construção de uma nova sociedade. Disponível em: http://publicadireito.com.br/artigos/?cod=601 c6bc71c748001. Acesso em: 23 Mar. 2017.

STURZA, Janaina Machado; MARTINI, Sandra Regina. As Dimensões da Sociedade através da Metateoria do Direito Fraterno: um espaço para a análise do direito à saúde. Revista de Sociologia, Antropologia e Cultura Jurídica, Curitiba, v. 2. n. 2, p. 990-1.008, jul./dez., 2016.

TAYLOR, Charles. et al. Multiculturalismo: examinando a política de reconhecimento. Tradução Marta Machado; revisão Pedro Duarte. Lisboa: Instituto Piaget, 1998.

TOURAINE, Alan. Pensar outramente: o discurso interpretativo dominante. Tradução Francisco Morais. Petrópolis: Vozes, 2009.

VIAL, Sandra Regina Martini. Sociedade Complexa e o Direito Fraterno. In: SANTOS, André Leonardo Copetti et al. (Org.). Constituição, sistemas sociais e hermenêutica: programa de pós-graduação em 
Direito da UNISINOS: mestrado e doutorado. Porto Alegre: Livraria do Advogado Ed.; São Leopoldo: UNISINOS, 2007.

WARAT, Luis Alberto. Por quien Cantan Las Sirenas. Chapecó: UNOESC/CPGD, 1996.

WARAT, Luis Alberto. Surfando na pororoca: ofício do mediador. Florianópolis: Fundação Boiteux, 2004.

Charlise Paula Colet Gimenez é doutora em Direito pela Universidade de Santa Cruz do Sul. Professora do Programa de Pós-Graduação stricto sensu em Direito - Mestrado e Doutorado, e do Curso de Graduação em Direito, ambos da Universidade Regional Integrada do Alto Uruguai e das Missões, campus Santo Ângelo/RS. Coordenadora do Curso de Graduação em Direito desta Instituição de Ensino Superior, campus Santo Ângelo/RS. Advogada.

E-mail: charliseg@santoangelo.uri.br.

Endereço profissional: Rua Universidade das Missões, n. 464, Santo Ângelo, RS. CEP 98802-470.

Paulo Adroir Magalhães Martins é doutoranda e Mestre Direito pelo Programa de Pós-Graduação stricto sensu - Doutorado e Mestrado em Direito da Universidade Regional integrada do Alto Uruguai e das Missões, Campus Santo Ângelo/RS. Especialista em Gênero e Sexualidade. Integrante do Projeto de Pesquisa (CNPQ) Direitos de Minorias, Movimentos Sociais e Políticas Públicas e do Projeto de Pesquisa Movimentos Sociais na Sociedade Multicultural. Integrante do Núcleo de Pesquisa de Gênero da Faculdade EST.

E-mail: paulo.adroir.martins@gmail.com.

Endereço profissional: Rua Universidade das Missões, n. 464, Santo Ângelo, RS. CEP 98802-470.

Rosângela Angelin é pós-doutora pela Faculdades EST, São Leopoldo-RS. Doutora em Direito pela Universidade de Osnabrueck (Alemanha). Docente do Programa de Pós-Graduação stricto sensu - Doutorado e Mestrado em Direito e 
da Graduação em Direito da Universidade Regional integrada do Alto Uruguai e das Missões, Campus Santo Ângelo/RS. Líder do Grupo de Pesquisa (CNPQ) Direitos de Minorias, Movimentos Sociais e Políticas Públicas. Coordenadora do Projeto de Pesquisa Direitos Humanos e Movimentos Sociais na Sociedade Multicultural. Vice-Líder do Núcleo de Pesquisa de Gênero da Faculdade EST. E-mail: rosangelaangelin@yahoo.com.br Endereço profissional: Rua Universidade das Missões, n. 464, Santo Ângelo, RS. CEP 98802-470. 